\title{
Primary versus secondary rehearsal in an imagined voice: Differential effects on recognition memory and perceptual identification
}

\author{
ALAN RICHARDSON-KLAVEHN and ROBERT A. BJORK \\ University of California, Los Angeles, California
}

\begin{abstract}
On each of a series of trials, subjects listened to four words presented by a female speaker and then imagined her rehearsing those words aloud for either 5 or $15 \mathrm{sec}$. Rehearsal was either primary (imagining the speaker repeat the words) or secondary (imagining the speaker associate the words). On a later test of auditory recognition memory, secondary-rehearsal items were recognized better than were primary-rehearsal items, and performance improved with rehearsal duration for both primary- and secondary-rehearsal items. By contrast, the positive effects of prior study for a later test of auditory perceptual identification did not depend on type or duration of rehearsal. These results are inconsistent with current two-process theories of recognition memory, but seem consistent with the distinction between data-driven and conceptually driven memory tests.
\end{abstract}

According to two-process conceptions of recognition memory, the judgment that an item occurred previously can be made either on the basis of the relative perceptual familiarity of that item, or on the basis of an effort to retrieve the context in which the item was initially encountered. In the earliest manifestations of two-process views, context retrieval was initiated only if the familiarity of the item proved an insufficient basis for a response (e.g., Atkinson \& Juola, 1974), but later versions have relaxed that assumption. The emphasis now is on the independence of the two forms of information (e.g., Jacoby \& Dallas, 1981; Johnston, Dark, \& Jacoby, 1985; Mandler, 1980; Mandler, Graf, \& Kraft, 1986).

According to Mandler (1980), the familiarity of an item depends on intra-item integration, which consists of "sensory and perceptual integrations of the elements of the target event ... independent of its relations to other events and representations" (p. 255). The number of repetitions that an item receives is considered a variable of prime importance for the occurrence of intra-item integration (e.g., Mandler, 1979); the improvement in recognition memory associated with increasing amounts of primary (rote) rehearsal (Woodward, Bjork, \& Jongeward, 1973) is therefore hypothesized to occur through an increase in the perceptual familiarity of the item. In contrast to perceptual familiarity, context retrieval depends on associations between the target item and other items that were rehearsed with the target item, and on associations between the target and the more general situational context at encoding (extra-item context: Bjork \& RichardsonKlavehn, in press; Geiselman \& Bjork, 1980). The ef-

These data were presented in November 1982 at the annual meeting of the Psychonomic Society, Minneapolis, MN. The research was facilitated by Grant 3186 from the Committee on Research, University of California, to the second author. Address correspondence to the first author at the Department of Psychology, Franz Hall, University of California, Los Angeles, CA 90024. fects on recognition memory of depth of processing (e.g., Craik \& Tulving, 1975), of organizational variables (e.g., Mandler \& Boeck, 1974), and of generate/read manipulations (e.g., Jacoby, 1983b) are hypothesized to occur through their influence on the likelihood of contextualassociative retrieval.

Geiselman and Bjork's (1980) results were consistent with the hypothesized independence of the two types of information. Their subjects rehearsed auditorily presented word triads imaginally, either in a prefamiliarized male or in a prefamiliarized female voice. In a subsequent recognition test, an item was presented either by the speaker who had presented it at encoding or by the other speaker. Increasing the duration of primary (rote) rehearsal improved recognition memory performance when the speaker's voice was the same at encoding and test, but not when it was different. By contrast, increasing the duration of secondary (elaborative) rehearsal improved performance, regardless of whether the same voice was heard at encoding and test. Geiselman and Bjork argued that primary rehearsal increased intra-item contextual associations (i.e., improved an item's perceptual integration), but resulted in a semantically impoverished memory trace. Preservation of the perceptual aspects of the item (such as voice) at test was therefore critical, because contextualassociative retrieval could not be used to support recognition of perceptually unfamiliar items. Secondary rehearsal, on the other hand, resulted in associations between the target and other encoded items, and in associations to the situational context. This form of information was available to support recognition judgments when the item was rendered perceptually unfamiliar by a change in intraitem (i.e., voice) context.

Jacoby and Dallas (1981, Experiment 1) adopted a different approach to the experimental separation of the forms of information hypothesized to support recognition judgments. They argued that the perceptual familiarity of 
an item could be indexed by the perceptual identifiability of that item measured tachistoscopically. They demonstrated that study of an item improved its later perceptual identifiability relative to "new" items-a priming effect-but that a manipulation of depth of processing of study items produced no effect on the extent of priming. As expected, the depth of processing manipulation produced a large effect on recognition memory performance, with semantic processing at study leading to better performance than phonemic or orthographic processing. Because depth of processing is assumed by the two-stage theory to influence selectively the likelihood of contextual-associative retrieval, this result is consistent with Jacoby and Dallas's claim that the perceptual identification test measures perceptual familiarity. Also consistent with this claim are their findings (Experiments $4 a$ and $4 \mathrm{~b}$ ) that repetition of items at study increased both perceptual identification priming and recognition memory performance (compared with a single-presentation control), and (Experiment 6) that a change in modality between study and test adversely affected both perceptual identification priming and recognition memory performance (compared with a same-modality control). The latter results are consistent with Jacoby and Dallas's viewpoint because the two-process theory assumes that rote repetition effects have a perceptual basis and are dependent on preservation of perceptual aspects of context between study and test.

The present study attempted to confirm the apparent relationship between Geiselman and Bjork's (1980) and Jacoby and Dallas's (1981) data. Our subjects rehearsed sets of four words that were presented auditorily by a female speaker. Rehearsal, performed imaginally, was either rote or elaborative; subjects were either to imagine the speaker repeating the words (primary rehearsal: PR) or to imagine her forming semantic associations between the words (secondary rehearsal: SR). Type of rehearsal (PR or SR) and duration of rehearsal $(5 \mathrm{sec}$ or $15 \mathrm{sec})$ were manipulated orthogonally within subjects. At test, items that had been rehearsed previously were mixed with new items and spoken by the same speaker who had presented the study items. Some subjects were asked to make recognition memory judgments concerning the test items; others received the test items mixed with white noise and attempted to identify each test item and write it down.

The two-process theory as elaborated by Jacoby and Dallas (1981) and others leads to some clear predictions. For recognition memory, SR should produce better performance than PR, because semantic-associative processing at study increases the probability that the study context of an item can be retrieved at test. Additionally, increasing rehearsal duration from 5 to $15 \mathrm{sec}$ should improve recognition memory for both PR and SR: Increasing PR duration is held to increase the perceptual familiarity of the item, and increasing SR duration affords the subject greater opportunities to forge associative connections between study words.

For perceptual identification, the predictions differ markedly from those for recognition memory: If the per- ceptual identifiability of an item indexes its familiarity, items given PR should be identified better overall than items given SR, because they receive more rote repetitions, which apparently integrate an item perceptually and render it more identifiable. In addition, the advantage of PR items over SR items should increase as rehearsal duration increases from 5 to $15 \mathrm{sec}$, in part because SR items receive a number of rote repetitions during the first few seconds of the rehearsal period, while the subject attempts to find associative connections between the words (e.g., Geiselman \& Bjork, 1980), and in part because the advantage of PR over SR items-in terms of cumulative number of repetitions-should increase as the duration of the rehearsal interval increases. The latter conclusion follows arithmetically from the assumption that the rote repetitions accorded SR items after the first few seconds, if any, are fewer per unit time than are those accorded PR items.

\section{METHOD}

\section{Subjects}

Subjects were 54 volunteers from an introductory psychology course at the University of California, Los Angeles. They received course credit for participating in the experiment.

\section{Design and Materials}

Type of rehearsal (primary vs. secondary) and duration of rehearsal (5 sec vs. $15 \mathrm{sec}$ ) were combined factorially, yielding four conditions (P5, P15, S5, S15). Both variables were manipulated within subjects. Type of test (recognition memory vs. perceptual identification) was manipulated between subjects. Thirty-six subjects received the perceptual identification test, and 18 subjects received the recognition memory test.

One hundred sixteen four-letter nouns were selected from the materials used by Pollatsek and Bettencourt (1976). These nouns were mostly concrete and of relatively high frequency. They were formed into 29 quadrigrams (sets of 4 words) by random assignment, subject to the constraint that there be no obvious relationships between the members of a quadrigram. Five quadrigrams were randomly selected to serve as practice items. The remaining 24 quadrigrams were randomly assigned into three sets of 8 items (Sets A, B, and C).

The encoding task consisted of 18 rehearsal trials, of which the first 2 were, unbeknownst to the subjects, practice trials. An initial order of conditions for the 16 critical trials was created such that each of the four rehearsal conditions (P5, P15, S5, and S15) occurred once within each block of four trials. Within blocks of four trials, the order of conditions was random, with the constraint that no level of either variable could occur more than twice consecutively in the list. Three input lists (I, II, and III) were created from this initial order so that, across the three lists, each set of words (A, B, and C) appeared under PR conditions, appeared under SR conditions, and did not appear in the study list. When a given set of words did not appear at study, it was used to form the "new" test items. From Lists I, II, and III a further three input lists (IV, V, and VI) were created: Each trial that had been assigned a 5-sec rehearsal interval in the initial ordering was now assigned a 15-sec interval, and vice versa. Within the recognition and perceptual identification groups, one-sixth of the subjects was randomly assigned to receive each input list. As a consequence, each quadrigram appeared in all four rehearsal conditions and as a new item across subjects. All input lists were recorded on audiotape by the same female speaker.

A single test list consisting of 96 individual words was presented to all subjects. This list contained all words from Sets A, B, and C. It was divided into four blocks of 24 items each. Each quarter of the test list contained items that had appeared in the corresponding quarter of the input lists: This procedure assured that retention interval was held approximately constant regardless of input serial position. Within blocks the order of words was random, subject to three conditions: (1) no more than two items from a given word set $(\mathrm{A}, \mathrm{B}$, or $\mathrm{C})$ could appear consecutively, (2) no more than five old items could appear consecutively, 
and (3) items that had appeared in the same quadrigram at input were separated by at least two other test items. Because each subject had rehearsed two of the sets of words at input (i.e., A and B, A and C, or $B$ and C), two-thirds of the test list consisted of old items, and onethird consisted of new items. The test list was recorded on audiotape by the same speaker who had recorded the input lists.

\section{Procedure and Apparatus}

The subjects served in groups of 3 . They were told that the purpose of the experiment was to find out how well they could rehearse words in terms of another person's voice, and that they would later be asked some questions concerning their ability to rehearse words in this manner. If they were told to repeat the words, they were to imagine the speaker repeating the words, paying careful attention to how the words would have sounded if the speaker were repeating them (PR). If they were told to associate the words, they were to imagine the speaker thinking aloud as she created semantic associations between the words (SR). The experimenter used one of the practice quadrigrams to give the subjects examples of how to perform SR in terms of the speaker's voice. The subjects could imagine the speaker stating semantic similarities or distinctions between words, or imagine her saying a simple sentence that connected the words. The subjects then listened to a tape of the speaker reading a 3-min passage from Davidson (1980). They were told to familiarize themselves thoroughly with the sound of the speaker's voice. No words in the passage appeared among the 116 words that were used as experimental stimuli.

The subjects received four practice trials. Two of these concluded the instruction phase and were known to the subjects to be practice trials. Following these trials, the subjects were permitted to ask questions. The remaining two practice trials immediately preceded the 16 critical rehearsal trials, and the subjects were not told that they were practice trials. These trials served to attenuate effects of primacy on the 16 critical items. The order of conditions in the practice trials was always S15, P5, S5, and $\mathrm{P} 15$, so that all four conditions were represented during practice. The five quadrigrams used during the instructions and practice trials were not tested.

Input and test lists were recorded using a Sony TC388 four-channel tape recorder and presented to the subjects over Electrophonic monophonic headphones via a Kenwood KA4004 amplifier. The speaker commenced each rehearsal trial by stating "ready." Four seconds later, she stated either "repetition" or "association" (depending on condition). Five seconds after the rehearsal instruction, she presented the four to-be-rehearsed words at approximately a 1 -sec rate. The rehearsal interval ( 5 or $15 \mathrm{sec}$, depending on condition) commenced $5 \mathrm{sec}$ following the presentation of the first word of the quadrigram, and was terminated by the ready signal for the next trial. The final trial was terminated by a ready signal, but no further instruction or item ensued. The duration of the 18 trials ( 2 practice plus 16 critical) was $7 \mathrm{~min} 12 \mathrm{sec}$.

Following the input trials, the subjects heard 20 familiar first names presented at a 7 -sec rate against a background of white noise (see description of perceptual identification test below). They attempted to identify each name and write it down. This 2-min 20-sec task served as a distractor to attenuate effects of recency on critical items, and as practice for subjects receiving the perceptual identification test. The subjects who received the recognition test were then instructed to indicate on a numbered test sheet whether or not each test word had been presented during the rehearsal trials. The subjects who received the perceptual identification test were told that they would hear noise that would interfere with their perception of the test items. They were simply to identify each item and write it down on the numbered test sheet. They were told that some test items might have occurred before in the experiment, but that they should not concern themselves with making old/new judgments.

Test items were presented at a 7-sec rate. Each item was preceded by a brief tone that served as a warning signal. For the perceptual identification test, the voice played back from the test tape was mixed with white noise from a Grason-Stadler $455 \mathrm{C}$ white noise generator. The voice amplitude was the same for the recognition and perceptual identification groups. Noise amplitude was set (on the basis of pilot data) at a level that produced an approximate identification error probability of .5 for items that had not received prior study. The duration of the test was $11 \mathrm{~min} 12 \mathrm{sec}$.

\section{RESULTS}

\section{Recognition Memory}

Mean hit proportions are presented in the top row of Table 1 . A $2 \times 2$ analysis of variance (ANOVA) was conducted on the number of hits per subject per condition (total possible $=16$ ). The effect of rehearsal type was significant $[F(1,17)=42.72, p<.001]$, with SR items being correctly judged old more frequently than PR items. The effect of rehearsal duration was also significant $[F(1,17)=8.23, p=.01]$. Items rehearsed for $15 \mathrm{sec}$ were correctly judged old more frequently than were items rehearsed for $5 \mathrm{sec}$. The interaction between type and duration of rehearsal was nonsignificant $(F<1)$.

\section{Perceptual Identification}

Mean proportions of items correctly identified are presented in the bottom row of Table 1 . A $2 \times 2$ ANOVA was conducted on the number of correctly identified old items per subject per condition (total possible $=16$ ). Neither the effect of rehearsal type $(F<1)$, nor the effect of rehearsal duration $[F(1,35)=1.24]$, nor the interaction of type and duration of rehearsal $(F<1)$ reached significance. Planned comparisons between correct identification proportions for old and new items revealed significant differences between each type of presented item (P5, P15, S5, and $S 15)$ and new items $(t \mathrm{~s}=2.5,3.1,3.47$, and 3.0, respectively; $d f \mathrm{~s}=35, p<.01$ in all cases). Old items in all four rehearsal conditions were identified better than were new items. The number of subjects (out of 36) showing an identification advantage for old over new items was consistent across rehearsal conditions: $23,24,22$, and 25 for the P5, P15, S5, and S15 conditions, respectively.

\section{DISCUSSION}

The recognition memory results of the current experiment constitute a conceptual replication of the results of Geiselman and Bjork (1980; data from same-voice conditions): SR produced better recognition memory than did PR, and performance improved with increasing rehearsal duration for both types of rehearsal. However, our perceptual identification results do not confirm the predictions of the two-process theory of recognition memory advocated by Jacoby (Jacoby \& Dallas, 1981; Johnston et al., 1985) and Mandler (1980; Mandler et al., 1986). In that theory, the improvement in recognition memory associated with increasing PR duration (such as that observed in the present study) is attributable to an increase in perceptual fluency, which in turn should be evident as an increase in perceptual identification performance. Although items given prior study were more identifiable at test than were nonstudied items, perceptual identification performance in the P15 condition was no better than performance in the P5 condition. Additionally, since PR items

Table 1

Mean Proportions of Old Words Recognized and Perceptually Identified as a Function of Type and Duration of Rehearsal

\begin{tabular}{|c|c|c|c|c|}
\hline \multirow{2}{*}{$\begin{array}{c}\text { Performance } \\
\text { Measure }\end{array}$} & \multicolumn{2}{|c|}{ Primary Rehearsal } & \multicolumn{2}{|c|}{ Secondary Rehearsa } \\
\hline & $5 \mathrm{sec}$ & $15 \mathrm{sec}$ & $5 \mathrm{sec}$ & $15 \mathrm{sec}$ \\
\hline \multicolumn{5}{|l|}{ Recognition } \\
\hline Hit Rate* & .58 & .66 & .81 & .86 \\
\hline \multicolumn{5}{|l|}{ Perceptual } \\
\hline Identification $\dagger$ & .62 & .64 & .64 & .65 \\
\hline
\end{tabular}

*False alarm rate $=.30 . \quad$ †Proportion of new words identified $=.55$. 
received a greater number of rote repetitions than did $S R$ items, $P R$ items should have been better identified than SR items, with the advantage of PR over SR items becoming more apparent at the longer rehearsal duration. However, there was no difference in perceptual identification priming between PR and SR items.

Supporters of the two-process theory of recognition memory may argue that the effect of PR duration on recognition memory was due to the unavoidable occurrence of semantic elaboration at the long (15-sec) rehearsal interval. If this were the case, PR duration might not be expected to have substantial effects on perceptual identification performance. However, this argument does not take into account the fact that the improvement in recognition memory resulting from increasing PR duration occurs only when perceptual context (e.g., voice, modality) is preserved between presentation and test (Geiselman \& Bjork, 1980), which suggests that the effects of PR on recognition memory have a perceptual, not a semantic, basis. Additionally, even if some semantic elaboration were occurring in the PR conditions, it is apparent from the large main effect of type of rehearsal on recognition memory that more rote processing was taking place in the PR conditions than in the SR conditions. According to the two-process theory, PR items should still be better integrated perceptually and more identifiable than should SR items. Together with other researchers (e.g., Feustel, Shiffrin, \& Salasoo, 1983; Squire, Shimamura, \& Graf, 1985), we question the plausibility of the assumption that perceptual familiarity, in the "déjà vu" sense of familiarity that we use when discussing recognition memory, is indexed behaviorally by ease of perceptual identification.

In accordance with the findings of Jacoby and Dallas (1981) and Jacoby (1983a, 1983b), our results show that prior presentation of a word enhances later perceptual identification of that word. Perceptual identification tests can be classified as data-driven memory tests because the subject is required to operate on external perceptual data at test (Jacoby, 1983b; Roediger \& Blaxton, 1987a, 1987b). Numerous studies have shown that facilitation in data-driven tests is dependent on preserving the physical form (e.g., language, modality) of the stimulus between study and test (for a summary, see Richardson-Klavehn \& Bjork, 1988). What is important for facilitation is that the subject has processed the external perceptual data prior to the test. The current results fit in with this task classification in that type and amount of imaginal processing, subsequent to an initial presentation, did not influence the amount of perceptual facilitation. Additionally, an unpublished experiment that we carried out prior to the present one found unreliable facilitation of later auditory perceptual identification when study words were presented visually and rehearsal was carried out in an imagined voice. Studies using visual data-driven tests (fragment completion: Roediger \& Blaxton, 1987a, 1987b; perceptual identification: Jacoby \& Witherspoon, 1982) have found priming effects when subjects imagined the typed (visual) form of auditorily presented words, but facilitation under these conditions was not always as large as that obtained with prior visual presentation.

The present results also fit in with a large body of data showing that facilitation in data-driven memory tests is insensitive to manipulations of conceptual types of processing at study, such as depth of processing, degree of elaborative processing, study time, difficulty of encoding, and intentional versus incidental learning (for a summary, see RichardsonKlavehn \& Bjork, 1988). In the current study there was a strong advantage of secondary over primary rehearsal for recognition memory, but no such advantage for perceptual identification. Although recognition memory tests clearly have a data-driven component, their high sensitivity to semantic elaboration at study sets them clearly apart from datadriven tests such as perceptual identification.

\section{REFERENCES}

Atkinson, R. C., \& Juola, J. F. (1974). Search and decision processes in recognition memory. In D. H. Krantz, R. C. Atkinson, R. D. Luce, \& P. Suppes (Eds.), Contemporary developments in mathematical psy- chology (Vol. 1): Learning, memory, and thinking (pp. 243-293). San Francisco: W. H. Freeman.

Bjork, R. A., \& Richardson-Klavehn, A. (in press). On the puzzling relationship between environmental context and human memory. In C. Izawa (Ed.), Current issues in cognitive processes: The Tulane Flowerree symposium on cognition. Hillsdale, NJ: Erlbaum.

Craik, F. I. M., \& Tulving, E. (1975). Depth of processing and the retention of words in episodic memory. Journal of Experimental Psychology: General, 104, 268-294.

Davidson, D. (1980). Psychology as philosophy. In D. Davidson (Ed.), Actions and events (pp. 229-239). New York: Oxford University Press.

Feustel, T. C., Shiffrin, R. C., \& Salasoo, A. (1983). Episodic and lexical contributions to the repetition effect in word identification. Journal of Experimental Psychology: General, 112, 309-346.

Geiselman, R. E., \& BJoRK, R. A. (1980). Primary versus secondary rehearsal in imagined voices: Differential effects on recognition. Cognitive Psychology, 12, 188-205.

JACOBY, L. L. (1983a). Perceptual enhancement: Persistent effects of an experience. Journal of Experimental Psychology: Learning, Memory, \& Cognition, 9, 21-38.

JACOBY, L. L. (1983b). Remembering the data: Analyzing interactive effects in reading. Journal of Verbal Learning \& Verbal Behavior, 22, 485-508.

JACOBY, L. L., \& DALLAS, M. (1981). On the relationship between autobiographical memory and perceptual learning. Journal of Experimental Psychology: General, 110, 306-340.

JACOBY, L. L., \& WITHERSPOON, D. (1982). Remembering without awareness. Canadian Journal of Psychology, 36, 300-324.

Johnston, W. A., DARK, V. J., \& JACOBY, L. L. (1985). Perceptual fluency and recognition judgments. Journal of Experimental Psychology: Learning, Memory, \& Cognition, 11, 3-11.

MANDLER, G. (1979). Organization and repetition: Organizational principles with special reference to rote learning. In L.-G. Nilsson (Ed.), Perspectives in memory research (pp. 293-327). Hillsdale, NJ: Erlbaum.

MandLeR, G. (1980). Recognizing: The judgment of previous occurrence. Psychological Review, 87, 252-271.

MANDleR, G., \& BoECK, W. (1974). Retrieval processes in recognition. Memory \& Cognition, 2, 613-615.

Mandler, G., Graf, P., \& Kraft, D. (1986). Activation and elaboration effects in recognition and word priming. Quarterly Journal of Experimental Psychology, 38A, 645-662.

Pollatsek, A., \& BetTencourt, H. O. (1976). The spaced-practice effect in the distractor paradigm is related to proactive interference but not to short-term store. Journal of Experimental Psychology: Human Learning \& Memory, 2, 128-141.

Richardson-Klavehn, A., \& BJoRK, R. A. (1988). Measures of memory. Annual Review of Psychology, 39, 475-543.

RoEdiger, H. L., \& BlaXTON, T. A. (1987a). Effects of varying modality, surface features, and retention interval on priming in wordfragment completion. Memory \& Cognition, 15, 379-389.

RoEDiger, H. L., \& BLAXTON, T. A. (1987b). Retrieval modes produce dissociations in memory for surface information. In D. S. Gorfein \& R. R. Hoffman (Eds.), Memory and cognitive processes: The Ebbinghaus Centennial Conference (pp. 349-379). Hillsdale, NJ: Erlbaum.

Squire, L. R., Shimamura, A. P., \& Graf, P. (1985). Independence of recognition memory and priming effects: A neuropsychological analysis. Journal of Experimental Psychology: Learning, Memory, \& Cognition, 11, 37-44.

WOODWARD, A. E., BJorK, R. A., \& JongeWARD, R. H. (1973). Recall and recognition as a function of primary rehearsal. Journal of Verbal Learning \& Verbal Behavior, 12, 608-617.

(Manuscript received for publication September 14, 1987.) 